\title{
DA FICÇÃO INTERATIVA À HIPERFICÇÃO: UM COMENTÁRIO SOBRE A GÊNESE DA LITERATURA ELETRÔNICA ESTADUNIDENSE
}

Cláudio Augusto Carvalho Moura ${ }^{1 *}$ ${ }^{1}$ Universidade Federal do Piauí, Teresina, PI, Brasil

\section{Resumo}

O presente artigo $^{1}$ revisita e discute o início da Literatura Eletrônica estadunidense a partir do nascimento da Ficção Interativa nos anos 1970. Na esteira, segue até a década de 1980 para avaliar os impactos da revolução informática no fazer literário, assim como o surgimento de um maior interesse teórico-crítico nas relações entre literatura e tecnologia. Para tanto, apresenta o surgimento dessa área de estudo através da história do subgênero Hiperficção a partir do programa de criação textual Storyspace (1987), criado por Michael Joyce e Jay Bolter, sua aquisição pela Eastgate Systems e o surgimento, como resultado, do único corpus literário coeso e reconhecido do gênero. Por fim, este estudo expõe e analisa a relação entre a Ficção Interativa e a Hiperficção no interstício em que se deu o declínio da primeira e a ascensão da segunda, na busca de entender seus motivos e impactos no cenário da Literatura Eletrônica.

Palavras-chave: Literatura Eletrônica Estadunidense; Ficção Interativa; Hiperficção; Storyspace; Eastgate Systems

\section{FROM INTERACTIVE FICTION TO HYPERFICTION: A COMMENTARY ON THE GENESIS OF AMERICAN ELECTRONIC LITERATURE}

\begin{abstract}
This paper revisits and discusses the early American Electronic Literature from the birth of Interactive Fiction in the 1970s. Then, it evaluates the impacts of the 1980's computer revolution on literary production along with the arising of a larger theoretical and critical interest in the relation literature vs. technology. To do so, it introduces the emergence of such scholarship through the history of the subgenre Hyperfiction from the creation of the textual software Storyspace (1987) by Michael Joyce and Jay Bolter, its acquisition by the Eastgate Systems and, as consequence, the emergence of the only cohesive and recognized literary corpus of the
\end{abstract}

\footnotetext{
*Professor de Teoria da Literatura e Literaturas de Língua Inglesa da Coordenação de Letras Estrangeiras (CLE) da Universidade Federal do Piauí (UFPI), Coordenador do Núcleo de Pesquisa em Literatura Digitalizada (NUPLID/UFPI) e do Projeto Morfologia da Ficção Especulativa (UFPI). Editor-chefe da Revista Texto Digital (UFSC). Doutor em Teoria Literária (UFSC). Seu e-mail é: ca.carvalho@ufpi.edu.br. ORCID: https://orcid. org/0000-0002-1386-1702.
} 
genre. Ultimately, this investigation exposes and analyzes the relationship between Interactive Fiction and Hyperfiction in the interstice when the former declined while the latter ascended to understand its reasons and impacts in the Electronic Literature scenario.

Keywords: American Electronic Literature; Interactive Fiction; Hyperfiction; Storyspace; Eastgate Systems 
Dentro da onda experimentalista que caracterizou a literatura mundial do século XX - na qual estão inclusas as vanguardas modernistas, como o dadaísmo, o concretismo e grupos como o OuLiPo -, a Literatura Eletrônica produzida nos Estados Unidos se mostrou um dos derradeiros empreendimentos expressivos do período. Muito embora, pode-se contestar, quantitativamente, essa dita expressividade, pelo menos no que diz respeito ao cânone e à Teoria Literária geral, o que já é muito, por si só. Até mesmo sua recepção, que sempre foi maior dentro de círculos acadêmicos estadunidenses restritos, deles se ramificando para o exterior, decaiu a partir do século XXI. Tal afirmação pode ser comprovada pelo hiato literário de doze anos da Eastgate Systems, a maior e mais relevante editora do gênero, no que diz respeito à publicação de obras inéditas de Literatura Eletrônica, uma vez que of day, of night (2004), de Megan Heyward, foi a última obra publicado nos anos 2000, enquanto a obra seguinte, Those Trojan Girls, de Mark Bernstein, só veio a ser publicada em 2016. Desde então, nesses últimos quatro anos, não foi lançado mais nenhum título. Nesse cenário, a crítica massiva sobrevive da produção do século passado, pois o gênero nunca mais alcançou expressividade semelhante, o que refletiu diretamente em sua produção.

No entanto, antes de continuar essa crítica, é preciso que sejam feitas algumas distinções ao abordar a Literatura Eletrônica. Primeiro, para especificar o meu recorte e, segundo, porque o campo é usualmente tomado como mais amplo do que de fato é. Antes de mais nada, quando aqui me refiro à Literatura Eletrônica, restrinjo-me à produção estadunidense dentro do gênero entre as décadas de $1970 \mathrm{e}$ 2000, enquadradas nos subgêneros Ficção Interativa e Hiperficção, ou seja, Ficção em Hipertexto. Porém, os pontos gerais que discuto são aplicáveis à Literatura Eletrônica como um todo, não apenas àquela produzida nos Estados Unidos.

Enquanto gênero, o conceito de Literatura Eletrônica mais difundido, e aqui adotado, provém da Electronic Literature Organization (ELO), através de Katherine Hayles. Em definição, Literatura Eletrônica dirá respeito a um tipo de "obra com um aspecto literário importante que se aproveita das capacidades e contextos fornecidos pelo computador, seja ele autônomo ou em rede" (HAYLES, 2007, p. 4, minha tradução ${ }^{2}$ ), exemplificada, mas não restrita, por Scott Rettberg a uma gama de obras que satisfaçam ou venham a satisfazer essa condição, tais quais:

- ficção e poesia em hipertexto, na internet e fora dela;

- poesia cinética apresentada em Flash e usando outras plataformas [que não o Flash];

- instalações de arte computacional que requerem que os expectadores as leiam ou possuam, de outro modo, aspectos literários;

- personagens que conversem, também conhecidos como "chatterbots";

- ficção interativa; 
- $\quad$ romances que se apropriem do formato de e-mails, mensagens SMS ou blogs;

- poemas e histórias gerados por computador, seja de modo interativo ou com base nele [computador];

- parâmetros fornecidos no início [de uma obra];

- projetos de escrita colaborativa que permitam aos leitores contribuir com o texto de uma obra;

- performances literárias online que desenvolvam novos modos de escrita. (RETTBERG, 2014, p. 172, minha tradução ${ }^{3}$ ).

Isso posto, de volta à sua conceituação, embora a expressão "aspecto literário importante" soe vaga e possa, por isso, ser vista como problemática, beirando à tautologia - o que Hayles mesma reconhece -, não se pode usar desse argumento para desconsiderá-la. Pois há de se levar em conta que não existe, ainda, uma forma unanimemente aceita de caracterizar a própria Literatura, que não evocar a qualidade do seu je ne sais quoi, que chamamos de literariedade, embora o próprio conceito de literariedade carregue toda uma problemática em si. Mas, partindo dele, é justamente essa literariedade o "aspecto literário importante" que a define como tal, seja o seu suporte físico (no caso, o impresso) ou virtual.

Há também a necessidade de se distinguir os estudos de Literatura Eletrônica daqueles que fazem uso de hardware e software para fins de análise e crítica literária e/ou textual. Assim como dos que tratam de questões voltadas à digitalização ou transposição de obras impressas para o meio eletrônico e seus impactos dentro do prisma de recepção dessas obras. Nesses casos, embora o computador seja um elemento comum aos três campos, todos possuem objetos distintos, e o domínio de um não se estende naturalmente aos outros.

Para além de seus pesquisadores, é compreensível o desconhecimento das obras de Literatura Eletrônica pelo público geral da grande área de Literatura dentro da academia, conforme corroborado por Bernstein (2016). Isso sem contar o dito leitor comum, fora dos muros das universidades. Tome-se, ora, a pesquisa-macro da qual deriva este artigo e o corpus selecionado para ela. Trata-se não só dos 59 títulos publicados pela Eastgate Systems entre os anos de $1990 \mathrm{e}$ 2016, mas do único corpus coeso dentro da Literatura Eletrônica a flertar diretamente com o cânone literário.

Dentre essas obras, pelo menos três títulos não devem soar estranhos aos ouvidos de alguém familiarizado com os escritos sobre Literatura Eletrônica: afternoon, a story (1990), de Michael Joyce; Patchwork girl (1995), de Shelley Jackson e Victory garden (1991), de Stuart Moulthrop - cuja análise desenvolvi em minha pesquisa macro, mas que, aqui, foge ao escopo deste artigo. Tratam-se tanto dos três títulos mais vendidos da Eastgate Systems (BERNSTEIN, 2017) quanto das maiores ocorrências em trabalhos acadêmicos sobre Literatura Eletrônica (RET- 
TBERG, 2012), ordenados de forma crescente com base nesses critérios. E se falo em não soarem estranhos, me refiro mais à possibilidade de se ter, pelo menos, ouvido falar sobre essas obras do que as ter lido. Especialmente nos dias de hoje, dada à obsolescência dos seus suportes para leitura.

À parte essa última questão, sua validação formal não é das mais expressivas fora do seu círculo teórico-crítico, à exceção das menções a afternoon, a story e a I have said nothing (1994), de Jane Y. Douglas, por Geyh, Leebron e Levy (1997) na Postmodern American Fiction: a Norton anthology. Menção essa que, a propósito, é usualmente retomada nos escritos sobre Literatura Eletrônica como algo qual uma chancela do gênero pelos pares da grande área. Porém, mesmo o mais otimista há de convir que isso é muito pouco se comparado à quantidade de referências aos movimentos e grupos citados no início dessa seção, disponíveis nos manuais gerais de literatura.

Fato é que, na prática, quase não se lê Literatura Eletrônica, mesmo entre seus pesquisadores. Basta checar o estado da arte do campo para se constatar o contrassenso que é o volume de teorização sobre a Literatura Eletrônica, hipertexto e outros correlatos enquanto objetos em si em detrimento às obras classificadas (ou classificáveis) como Literatura Eletrônica. E boa parte dessa teorização resulta, desde o início, na distorção e bricolagem de teorias pré-existentes - em especial estruturalistas e/ou pós-estruturalistas - na intenção de se ter algo novo a acrescentar; aparentemente, mais pela iminência do novo do que pelo rigor e qualidade do material teórico resultante. É aquilo que Alan Sokal e Jean Bricmont (1999) chamaram relativismo pós-moderno, o abuso terminológico somado à extrapolação de ideias, ambos aplicados fora do seu contexto/área do conhecimento original, num exercício de erudição que pode ser bastante convincente, especialmente se assinado por um nome consagrado dentro da academia. E mesmo em se tratando de afternoon, a story, Patchwork girl e Victory garden, no que diz respeito à qualidade das análises em sua fortuna crítica, seria possível aplicar o princípio da lei de Sturgeon, uma vez que inúmeros artigos, capítulos, livros, dissertações e teses sobre essas três obras se debatem superficialmente por sobre os mesmos aspectos e chegam às mesmas conclusões. $\mathrm{O}$ que faz com que um leitor do gênero questione a familiaridade do crítico com o seu objeto de análise.

Essa não é simplesmente uma opinião minha, enquanto pesquisador da área, mas algo que tenho ouvido pessoalmente, ao longo dos anos, de muitos dos autores de Hiperficção da própria Eastgate School, aqui mencionados, além de outros autores e teóricos de Literatura Eletrônica com os quais convivo. Realidade que pode ser facilmente comprovada por qualquer um que se disponha a realizar uma pesquisa séria e de fôlego sobre sua fortuna crítica. Pois só a partir dela será possível notar que há uma discrepância entre os registros que compõem uma dita narrativa oficial da Literatura Eletrônica produzida nos Estados Unidos. Narrativa essa que se construiu e se consolidou - concomitante, interdependente e correlacionada - à produção artística, teórica e crítica do gênero ao longo das três últimas décadas do século XX, relacionando-se, dessa feita, às lacunas existentes nesses três mesmos campos. Tal qual uma versão higienizada que foi editada e 
reformulada no decorrer do seu processo de formação, sendo hoje aceita e disseminada sem grandes questionamentos, sob a chancela de suas fontes primárias e secundárias mais proeminentes. Não há, contudo, obviedade nessa afirmação. Pelo contrário, são muitas as fontes que corroboram uma mesma linha narrativa coesa. Seja pela falta, desconhecimento, omissão, distorção ou negligência de relatos à contramão dessa História Literária, ela se mantém e se ratifica como tal; assumindo as vezes de axioma.

À repetição, seja num contato inicial às fontes de referência do gênero ou em um estudo mais aprofundado do estado da arte da Literatura Eletrônica, variando o nível de detalhes, um pesquisador, quer experiente ou iniciante no campo, encontra um quadro histórico coerente e bem fundamentado, que entrelaça prática, teoria e crítica literária. Quadro esse no qual, via de regra, narrativas que compõem uma história do gênero são relatadas - ou atribuídas - de forma convergente, através da ótica dos personagens e grupos alçados ao papel de seus protagonistas. Logo, é compreensível que essa narrativa oficial se perpetue, uma vez que suas fontes se encontram em um ciclo de retroalimentação e, por consequência, retrovalidação contínuo, o qual lhes confere verossimilhança e verificabilidade.

Como pano de fundo desse cenário, tem-se um argumento de autoridade sutil, que só se faz visível a partir do momento em que se perscruta a vida literária desse círculo, ponto que merece atenção. Vida literária essa que, a partir da observação de sua aplicação empírica dentro da obra de Brito Broca (2005), enquanto conceito, abarca o entorno dos acontecimentos, relações e contextos nos quais determinados personagens viveram - neste caso, autores, editores, teóricos e críticos de Literatura Eletrônica, e quaisquer outros que com eles se relacionaram ou (mas, não obrigatoriamente) tiveram alguma influência sobre suas produções, seja direta ou indiretamente, em níveis variáveis - dentro de um determinado período, estendendo-se para além dos produtos oficiais de sua vida pública.

Nesse ponto, a vida literária difere da História Literária por sua inclinação à biografia, do tipo não autorizada, e interesse em pormenores através de vias marginais. Para tanto, recorre a registros e fontes não raras vezes desconsiderados, pelos motivos que forem, dentro do que se atribui como uma história oficial para, só então, revisitá-la, nunca desconsiderando a História em seu sentido macro. Como objetivo, busca vislumbrar uma narrativa multidimensional a partir do material humano, a memória, os relatos ou registros - oficiais ou não - e os pontos de vista.

Sua abordagem do literário se aproxima da fenomenologia de Edmund Husserl (2001), por mover o foco reflexivo inicial de construções subjetivas como a teoria e a história para a observação e análise da ação humana. Desse modo, parte para examinar essas subjetividades por meio de um exercício hermenêutico, em vez de recontar versões mais ou menos detalhadas, com edições que não alteram o curso geral da narrativa comum, apenas corroboram o que se tem como história oficial do gênero.

Por ironia, essa mesma história oficial é construída e ratificada em cima de uma pretensa vida literária das figuras mais notáveis que compõem os círculos da Literatura Eletrônica estadunidense. Trata-se, na maioria das vezes, de relatos 
e impressões fornecidos diretamente por essas figuras ou chancelados por elas. Alguns desses embasados por fontes documentais verificáveis, outros tantos não; mas, a despeito, aceitos sem grandes contestações. Argumentum ad verecundiam, como dito anteriormente. Nesse caso, constitui-se também enquanto uma espécie de biografia - só que do tipo autorizada -, construída à base de uma autobiografia do sujeito, diferindo de autor para autor pela riqueza de detalhes. Um modelo com variantes que se repete à exaustão. Válido, embora questionável em vários pontos, mais como tentativa de resgate histórico-literário, na maioria das vezes, do que como conjunto teórico-crítico em si, pois se trata de um recorte que se fecha apenas naquilo que se convencionou mostrar.

Daí a necessidade de examinar sua história num exercício para além de um simples estado da arte, vez que a organização formal de uma crítica voltada para os estudos das relações entre as tecnologias computacionais, a escrita e a leitura, sejam elas literárias ou não, deu-se, gradualmente, a partir do processo de massificação e incorporação dessas tecnologias na/pela sociedade nos mais rotineiros campos, em um cenário que, atualmente, beira a onipresença.

\section{Ficção Interativa: (o prenúncio de) um gênero atrelado à tecnologia}

Ainda na década de 1970, enquanto os computadores pessoais demorariam alguns anos até se tornarem realidade, sua tecnologia, mesmo restrita, deu os primeiros indícios de uma aplicabilidade ao fazer literário para além da simples datilografia, corporificada na Ficção Interativa. Conforme Marie-Laure Ryan (2005), a Ficção Interativa constitui o primeiro gênero narrativo cuja criação e recepção se deram exclusivamente dentro do ambiente eletrônico do computador. Um híbrido entre jogo e literatura, sendo comumente referido como Jogos de Aventura; nomenclatura que se deve, em sua concepção original, ao fato da Fiç̧ão Interativa não ter sido idealizada como gênero literário, mas como um jogo textual baseado no gênero fantasia. Considerada a precursora da Literatura Eletrônica, ela é comumente tomada como caminho para entender o seu início. Esse papel que lhe foi atribuído não é, de todo, incorreto; embora, à contramão, julgo que, no que concerne à Literatura Eletrônica, o estudo da Ficção Interativa se faz mais útil em apontar os possíveis porquês de sua decadência.

Sobre o seu nascimento, conforme Nick Montfort (2003) e Andrew Hutchison (2009), a Ficção Interativa teve seu início com o primeiro protótipo de Colossal Cave Adventure (1972), de William Crowther, criado em um Mainframe - tipo de computador possuído apenas por instituições como universidades nas décadas de 1960-1970 -, distribuído via ARPANET - a rede de comunicação e compartilhamento de arquivos entre computadores precursora da internet, criada apenas para fins militares - e, só então, desenvolvido a partir do original de Crowther por Don Woods entre 1975-1977 com o nome Adventure (CROWTHER; WOODS, 1977). Ambas as versões tratam-se de um programa exploratório interativo baseado apenas em texto, no qual o software responde descritivamente, por meio de uma tecnologia chamada analisador, aos comandos de um 
jogador, via teclado, a partir de uma gama de possibilidades restritas, previstas por sua programação. Autoexplicativo, o programa disponibilizava, em uma tela intitulada $A j u d a$, instruções operacionais básicas aos seus usuários, a fim de que dominassem sua jogabilidade. Característica que seria, em um futuro próximo, incorporada pela Hiperficção, visto que suas obras passariam a vir com manuais de instruções próprios.

Dentro das limitações tecnológicas de sua época, Crowther recriou em seu protótipo uma aventura exploratória ambientada nas Cavernas Mamute do estado do Kentucky (EUA). Esse tipo de simulação, com direito a personagens ficcionais fantásticos (incluindo o próprio jogador, através de um avatar), tesouros e desafios típicos de jogos (enigmas, charadas etc.), lembra, em certo ponto, a experiência dos seus contemporâneos Role Playing Games (RPGs), como Dungeons \& Dragons (1974), que logo viraram também um fenômeno. Porém, diferente dos RPGs - que eram jogados em grupo e usavam como base seus manuais físicos, fichas, dados etc., mas principalmente a comunicação presencial entre os seus participantes -, o jogador de Ficção Interativa interagia apenas com um computador. E como sua jogabilidade era limitada pela tecnologia da época, cabia ao jogador imaginar, com base apenas nas descrições que o programa lhe fornecia, todo um mundo e ações à sua volta.

No que concerne tanto às descrições quanto ao corpus cognoscível do analisador (MONTFORT, 2003), o grande desafio para Crowther na criação do protótipo foi a implementação de uma linguagem mais primária que facilitasse a imersão na simulação. Para tanto, ele usou como parâmetro sintático-semântico suas duas filhas pequenas.

Essa interface só de texto era necessária porque os computadores dos anos 1970 tinham muito pouca ou nenhuma capacidade visual, o que permitiria qualquer renderização/descrição audiovisual das cenas, ou a interface de "apontar e clicar" que se tornaria mais comum perto do final dos anos 1980. O sistema usa uma técnica chamada "analisador" para verificar as entradas [de texto] do usuário e então responder apropriadamente, ou, ainda, como é frequentemente o caso, solicita que o jogador reescreva a entrada de modo que o analisador possa lhe responder de uma forma útil. Essa técnica de análise de linguagem tem por objetivo permitir que o jogador use uma linguagem normal para interagir com o jogo apenas através do teclado (HUTCHISON, 2009, p. 52-53, minha tradução ${ }^{4}$ ).

A partir daí, o diálogo com a máquina dentro de um simulacro regido por uma Inteligência Artificial (IA) rudimentar possibilitava ao usuário da época, sem, necessariamente, conhecimentos prévios de programação, experimentar uma imersão tecnológica até então possível somente aos personagens da Ficção Científica. Bastava, para isso, possuir um computador - realidade que foi se tornando cada vez mais acessível, dado o surgimento crescente de vários modelos dentro das mais variadas faixas de preço ao longo da primeira metade dos anos de 1980 - e um disquete com o jogo, vez que o acesso à ARPANET era restrito. 


\section{A Ficção Interativa enquanto produto}

Criado sem fins lucrativos, o código-fonte de Adventure foi distribuído gratuitamente, o que permitiu não somente a criação de incontáveis versões subsequentes, mas também sua portabilidade para outras máquinas. Tal ação foi responsável por garantir, de acordo com Hutchison (2009), não apenas a sobrevivência de várias dessas versões nos dias atuais, mas do próprio código, que se encontra online, ainda disponível para download nos dias de hoje. Contudo, a despeito de sua obra precursora não visar ao lucro e ter inspirado muitos de seus entusiastas a criar e a distribuir suas próprias versões por pura diversão, alguns fãs de Adventure enxergaram na iniciativa o potencial para o nascimento e estabelecimento de um novo nicho de mercado que poderia ser - e assim se provou - bastante lucrativo.

Atenta a essa oportunidade, a companhia Infocom foi fundada, em 1979, com foco na produção e comercialização de Jogos de Aventura. Como resultado, já no ano seguinte, 1980, foi lançado Zork I, o mais bem sucedido título de Fiç̧ão Interativa. Sua versão beta havia sido finalizada no ano anterior por Marc Blank e Tim Anderson, e anunciada por seus criadores como "um jogo sucessor de Adventure" (HUTCHISON, 2009, p. 56, minha tradução ${ }^{5}$ ).

Após seu lançamento, Zork I foi um grande sucesso comercial - chegando a integrar o catálogo postal da RadioShack, a maior cadeia estadunidense de eletrônicos à época- seguido de várias versões posteriores e outros títulos em disquete. Suas vendas somaram, apenas no ano de 1984, um total de 10 milhões de dólares. Nesse mesmo ano, em vistas à grande aceitação do seu produto no mercado, a Infocom apostou na adaptação de obras literárias impressas para o formato de Ficção Interativa, como foi o caso de The hitchhiker's guide to the galaxy (1984), de Douglas Adams, adaptado por Steve Meretzky (ADAMS; MERETZKY, 1984).

Porém, o início dos anos 1980 representaria também o surgimento de uma nova tecnologia que, ao passo que impulsionaria a Infocom, seria responsável por lhe abreviar a sobrevida àquela década. Trata-se do computador pessoal, ferramenta que revolucionaria, dentre tantos outros setores, o entretenimento, e que possibilitaria expandir o embrião literário notado na Ficção Interativa para uma nova empreitada: a já mencionada Hiperficção. Subgênero neófito que, nesse novo cenário, se tornaria sinônimo de Literatura Eletrônica e transferiria o protagonismo dos títulos da Infocom, enquanto objetos de estudo dos interessados nas relações entre literatura e tecnologia, para nomes como Michael Joyce, Jay Bolter e Mark Bernstein, e tornaria a pequena Eastgate Systems a maior referência do gênero no final do século XX. Por isso, precisarei interromper a narrativa sobre a Fiç̧ão Interativa - que, por si, se constitui como relativamente curta - por aqui, para retomá-la mais à frente, concomitante à da Hiperficção, mostrando a relação entre o declínio da primeira frente à ascensão da segunda, especialmente no que tange à reação dos autores de Hiperficção. 
Os anos 1980 e a história do romancista que se apaixonou por uma máquina

Dando continuidade a uma tradição iniciada em 1927 que se mantém na atualidade, a edição especial da revista TIME de 3 de janeiro de 1983 anunciou o "Homem do ano" de 1982. A grande diferença entre aquela edição e suas anteriores foi que, para o ano em questão, não foi escolhido um homem - que a imprensa à época especulava ser Steve Jobs -; mas sim, a Máquina do ano: o computador, para o qual foi dedicada uma seção inteira da revista, composta por editorial seguido de sete artigos correlatos.

Logo na chamada de capa, The computer moves in - também título do primeiro artigo da seção, de autoria de Otto Friedrich (1983) - fica claro à que veio a edição de 1983, que acabou por formalizar, enquanto registro histórico, o estabelecimento do que viria a ser chamado de revolução/era digital. Não que os computadores fossem de todo desconhecidos da população, mas sua presença se restringia às universidades, órgãos do governo (ou seus prestadores de serviços), militares e corporações tecnológicas. E até então, o que se entendia por computador remetia às grandes estações de trabalho fixas para uso restrito (workstations) às quais a maioria dos civis só tinha acesso através de fotos e da televisão; ou então da literatura e do cinema, que usaram da licença poética para construir todo um imaginário acerca dessa tecnologia; o que nem sempre correspondia à realidade.

Conforme Alfred Dupont Chandler (2009), os microcomputadores começaram a ser comercializados apenas a partir da segunda metade da década de 1970, com destaque para as máquinas fabricadas pela Apple Computer, Commodore International e RadioShack, em 1977. Na sequência, em 1981, o lançamento do IBM Personal Computer (IBM PC) pela IBM adicionou ao vocabulário popular o termo Computador Pessoal - embora no Brasil seja comum o uso da sigla anglófona PC (Personal Computer) para se referir às versões de mesa (desktops) e, por vezes, às versões portáteis (laptops) - e trouxe uma nova máquina, operacionalmente mais amigável que as anteriores. Mas foi só em 1983, entretanto, com o lançamento do Apple Lisa e sua interface gráfica de usuário, que a produção e a comercialização em massa de computadores se consolidou, confirmando, em um intervalo de duas semanas - o Apple Lisa foi lançado em 19 de janeiro de 1983, 16 dias após a edição da TIME -, que as previsões da revista já vinham se cumprindo. Não seria surpresa, contudo, embora não o possa aqui afirmar, se isso se tratasse de uma estratégia de marketing acordada entre a Apple e a TIME.

Conjecturas à parte, em 1982, um ano antes da edição da TIME citada anteriormente e dois anos antes do pico de popularidade da Ficção Interativa, Michael Joyce, professor do Jackson Community College, em Jackson, Michigan, havia ganhado o Great Lakes new writers award. Tratava-se de um prêmio literário regional pelo seu primeiro romance, The war outside Ireland (JOYCE, 1982), não traduzido para o português. Romance esse que, de acordo com Matthew Kirschenbaum (2008), chamou a atenção do sociólogo e pianista de jazz Howard (Howie) Becker, 
o que iniciou uma vasta correspondência entre ambos. E dessa correspondência veio a descoberta de um interesse compartilhado entre os dois: o computador.

À época, Joyce (1995), um leitor ávido de revistas de computação, segundo ele mesmo, tinha acabado de adquirir seu primeiro computador, um Apple II. Uma carta de Joyce a Becker, que se tornou o que ele chamou de seu "xamãtecnológico", datada de 7 de janeiro de 1982 - hoje parte do arquivo dos Michael Joyce Papers, sob os cuidados do Harry Ransom Center (HRC), na Universidade do Texas em Austin - documenta o misto de fascínio e estranhamento que o computador causou em um Joyce ainda neófito nos meandros da computação:

Então, eu estou escrevendo para perguntar o que fazer depois que se liga ele [o computador]. Sério, eu tenho passado longas noites sem a menor noção de tempo dando um jeito de aprender sozinho isso e aquilo, e essa noite eu praticamente tive que me virar pelo avesso procurando por alguma correspondência, e eu penso que a mudança é salutar. Me maravilha o quão atraente o computador é, o modo como eu posso escrever tão livremente nele (restrito a periódicos até agora, até eu ser capaz de entender as minúcias do [editor de texto] Applewriter), e como o tempo passa rápido quando estou em frente ao seu terminal. Mas eu estou ciente de sua dimensão particular, uma sensação de que o tempo que dedico a ele é algo profundo, silencioso; geométrico, de alguma forma. Possivelmente isso seria o resultado de não ter a impressora ainda, mas eu duvido. Eu acho que tem mais a ver com a qualidade absolutamente elementar das informações com as quais o Apple [II] lida, com a beleza agradável das fileiras de chips quando a tampa está aberta, a prazerosa satisfação geográfica da memória simultaneamente no disco e na própria memória [humana], a fita cinza enervada que as liga. Isso sim é uma tecnologia sedutora.

Um amigo perguntou se não me aborrecia o fato de não haver nenhum papel à minha frente, como agora, e eu tive que responder honestamente que usar o computador me pareceu, no mínimo, uma forma mais autêntica de captar a linguagem como eu a entendo. Para mim, as palavras se parecem mais com essa colmeia de insígnias eletrônicas do que essas batidas de carbono à minha frente. Parece certo interpretar a linguagem como uma série de marcas alternadas, cargas e descargas, zeros e uns. A forma que ela toma ao final é quase acidental; será que nós sempre escrevemos sonhos? (Eu estou surpreso com o peso do 'agradável' e 'prazeroso' acima, mas são essas as palavras que me vêm. Um computador, um Apple em especial, é uma máquina muito perfeita) (JOYCE, 1982, minha tradução ${ }^{6}$ ).

Todavia, embora Joyce (1995) considere Becker o primeiro apoiador de suas empreitadas literárias no mundo eletrônico, a primeira pessoa a tomar uma ação prática nesse sentido foi Natalie Dehn, à época membro do Laboratório de IA de Yale, liderado por Roger Schank.

Joyce a descobriu ao ler um artigo sobre experimentos literário-computacionais que ela assinava e que buscavam, segundo sua descrição, ensinar computadores a escreverem romances. O nome do artigo em questão era Story generation after TALE-SPIN (1981) e havia sido publicado no volume 1 dos Proceedings of the 7th International Joint Conference on Artificial Intelligence, a IJCAI'81. Nele, 
Dehn introduz e descreve o software AUTHOR, ainda em desenvolvimento por sua equipe da época, a partir do software TALE-SPIN, que era a ferramenta de autogeração de histórias por meio de IA mais recente até então; e logo os dois, Joyce e Dehn, passaram a se corresponder.

O interesse inicial de Joyce ao contatar Dehn era que lhe fosse recomendado não um software que gerasse suas próprias histórias, mas um que permitisse a ele concretizar uma ideia de obra que lhe ocorreu após seu contato com as potencialidades do computador.

O que eu queria realmente fazer, eu descobri, não era simplesmente mover um parágrafo da página 265 para a página 7 , mas fazer isso quase que incessantemente. Eu queria, muito simplesmente, escrever um romance que mudaria em suas leituras sucessivas, e fazer essas versões cambiantes de acordo com as conexões que eu havia por algum tempo descoberto naturalmente no processo de escrever, as quais eu queria que meus leitores partilhassem. Aos meus olhos, parágrafos em várias páginas diferentes poderiam muito bem combinar com parágrafos de muitas outras páginas, apesar de que com efeitos diversos e por motivos diferentes. Tudo o que me impedia de fazer aquilo era o fato de que, pelo menos no impresso, um parágrafo inevitavelmente sucede um outro. Me parecia que se eu, enquanto autor, podia usar um computador para mover os parágrafos no texto, não seria tão complicado para os meus leitores fazerem a mesma coisa seguindo algum esquema pré-determinado por mim (JOYCE, 1995, p. 31, minha tradução ${ }^{7}$ ).

Segundo Joyce (1995), a reação de Dehn foi lhe informar que não existia tal software. Apesar disso, de suas correspondências subsequentes, surgiu um convite para que Joyce fosse professor visitante em Yale no ano seguinte, 1984, em seu laboratório. Tratava-se, justamente, do ano de maior vendagem da Infocom. Além do convite, veio também a sugestão de um contato: Jay David Bolter, professor de Letras Clássicas da Universidade da Carolina do Norte - Chapel Hill (UCN) que havia sido professor visitante em seu laboratório no ano anterior e que, segundo Dehn, compartilhava dos mesmos interesses de Joyce.

\section{O encontro com o professor de Literatura que sabia programar}

Diferente de Joyce, que via na computação um hobby, Bolter, além de possuir formação em Grego (1973) pelo Trinity College da Universidade de Toronto e um PhD em Letras Clássicas (1977) pela UCN, era mestre em Ciência da Computação (1978) pela mesma universidade, uma formação incomum para aqueles tempos. Em entrevista publicada em Memory machines: the evolution of hypertext, de Belinda Barnet (2013), Bolter afirmou ser, à época de seu doutorado, o único aluno de sua classe que possuía algum conhecimento de computação.

$\mathrm{O}$ ano em que Bolter completou seu mestrado foi também o ano no qual começou a trabalhar como professor assistente de Letras Clássicas na própria UCN. Coincidência ou não, seu departamento havia iniciado, em 1975, uma empreitada pioneira de informatização de textos clássicos liderada por David Woodley Packard, com quem trabalhou por dois anos no sistema IBYCUS para pro- 
cessamento de textos gregos, que foi deixado aos seus cuidados após a saída de Packard da UCN. Foi a partir dessa experiência que Bolter passou a se interessar pelas aplicações da computação na literatura.

Ciente dos trabalhos da equipe de Dehn, Bolter partiu para um período como professor visitante em Yale (1982-1983). Porém, como ele mesmo informou à Barnet (2013), seu interesse não residia na geração automática de textos literários via IA, mas sim no uso da computação como ferramenta que enriquecesse a experiência literária, em especial dos textos clássicos. Assim, ao final, apesar de todo o intercâmbio de conhecimento que sua estadia em Yale lhe proporcionou, o que lhe rendeu, inclusive, um livro: Turing's man: western culture in the Computer Age (BOLTER, 1984), foi no seu encontro com Joyce que Bolter realmente encontrou alguém que nutria aspirações semelhantes às suas.

Intermediada por Dehn, a parceria entre Bolter e Joyce teve início oficialmente em setembro de 1983 (BOLTER; JOYCE, 1986). No período em que os dois se conheceram, enquanto as ambições de Joyce se resumiam, em suas próprias palavras, à ideia vaga de um programa que possibilitasse a criação de "ficções múltiplas" (BOLTER; JOYCE, 1986, p. 12, minha tradução ${ }^{8}$ ), Bolter, além de sua formação, já tinha uma certa experiência prática no campo.

No primeiro encontro, Bolter apresentou a Joyce o software que ele mesmo havia criado, o TEXT, introduzido e descrito no artigo The idea of literature and the electronic medium (BOLTER, 1985), que se baseava em uma premissa de interatividade e multiplicidade semelhante à de Joyce, porém, mais simples. Joyce enxergou, conforme Barnet (2013), a ação de Bolter como uma espécie de oferta que apontava para as possibilidades daquela parceria, caso ela se consolidasse. E foi esse o caso, pois o programa de Bolter viria a ser o embrião do Storyspace, o software de criação textual que definiria a Literatura Eletrônica estadunidense.

À época, a base teórico-tecnológica que permitiu a Bolter e Joyce (1986) enxergarem o potencial real de execução do seu projeto foram os trabalhos de teóricos renomados da computação como Vanevar Bush, Douglas Engelbart e Theodor Nelson, assim como na existência e no êxito comercial da Ficção Interativa. Já no campo da computação, havia os desenvolvimentos empreendidos nos ambientes computacionais, como as estações de trabalho Xerox Star, Sun e Apollo, assim como as implementações do UNIX. Havia, também, os sistemas operacionais como o Valdocs, da Epson, o Lisa e o Macintosh, da Apple, com seus sistemas mnemônicos associativos e suas estruturas de dados; e aplicações integradas que permitiam a manipulação de informação através de links, como era o caso das várias versões do Lotus e o Symphony.

Outra grande influência reconhecida por Bolter e Joyce (1986) - mesmo ambos afirmando, desde o início, que o Storyspace não se tratava de forma alguma de um programa de IA - foi a equipe de Schank em Yale, em especial os programas TALE-SPIN, de James Meehan, e AUTHOR, de Dehn. Esse intercâmbio intelectual influenciou sua forma de pensar tanto as relações entre o computador e a escrita, quanto sua prática no design de programas. Desse modo, por volta de janeiro de 1984, menos de um semestre após terem se conhecido, os dois come- 
çaram a rascunhar uma série de considerações ligadas ao programa que ambos desenvolveram a partir do TEXT, que se chamou TALETELLER.

Em março do mesmo ano, Joyce escreveu Draft of pseudocode for text processor (JOYCE, 1984), composto por uma série provisória de especificações de design; enquanto Bolter desenvolveu uma versão de trabalho complexa do programa. Paralelamente, Bolter havia passado a integrar também o grupo de pesquisa liderado pelo chefe do Departamento de Ciência da Computação da UCN, seu colega John Smith. Smith era o responsável pelo desenvolvimento de "um sistema de suporte de escrita em estrutura arbórea" (BOLTER; JOYCE, 1986, p. 13, minha tradução ${ }^{9}$ - que eles relataram, erroneamente, se chamar PROSE, mas que, na verdade, se chamava WE (Writing Environment), conforme observado por Barnet (2013) - que também exerceu grande influência sobre o Storyspace.

Posteriormente, em abril, Bolter e Joyce se juntaram a Jerome Krakowiak, professor do Departamento de Ciência da Computação do Jackson College, e redigiram o documento que inspirou o Storyspace, que até então não tinha ainda esse nome, intitulado Notes on the collaborative effort to create a data structure for interactive fiction (BOLTER; JOYCE; KRAKOWIAK, 1984). A partir desse documento, Bolter e Joyce conseguiram formular, pela primeira vez, uma ideia mais precisa do core que viria a constituir a base do sistema que ambos se propunham a construir, que seria uma implementação do TALETELLER chamada TALETELLER 2:

A estrutura de dados relativamente complexa que acordamos envolve, no entanto, técnicas conhecidas em geral para representação de dados em computadores. O método proposto envolveu o armazenamento de "nodos" que consistiam em texto, imagens armazenadas digitalmente, e assim por diante, juntamente com a rede de "links" entre esses nodos, de modo que tanto o criador quanto o público poderiam processar, transferir e recebê-los de modos sutis notáveis. Envolveu, mais particularmente, a combinação da estrutura de dados hierárquicos relativamente familiar e eficiente conhecida como árvore com a estrutura de dados menos familiar, mas mais robusta, conhecida como redes ou gráficos (BOLTER; JOYCE, 1986, p. 13, minha tradução ${ }^{10}$ ).

Ainda na primeira metade de 1984, baseados na experiência adquirida com a criação do TEXT e TALETELLER e sob o argumento do desenvolvimento do TALETELLER 2, Bolter e Joyce submeteram um projeto para financiamento de pesquisas acadêmicas à Fundação Markle, o qual foi selecionado e agraciado. Como resultado, foram concedidos fundos para o desenvolvimento de sua pesquisa no ano de 1985. Nesse mesmo período, Joyce havia tirado uma licença sabática para se juntar ao pessoal do Laboratório de IA de Yale em New Haven (Connecticut), enquanto Bolter continuaria em Chapel Hill, trabalhando na implementação do TALETELLER, originalmente criado num IBM, para Macintosh.

Todo o processo de criação do Storyspace é descrito em detalhes no relatório apresentado por Bolter e Joyce à Fundação Markle, intitulado Storyspace: a tool for interaction (BOLTER; JOYCE, 1986). O Markle Report, como é conhecido o documento, também integra a coleção Michael Joyce Papers, do Harry Ram- 
son Center. Trata-se de um documento tão raro que, afora o próprio Joyce, só é referenciado com propriedade por Barnet (2013) e Kirschenbaum (2016), que teve acesso a seu conteúdo in loco, mas não possui nenhuma cópia. Fato é que a única cópia (física ou digital) que existe, segundo Joyce (JOYCE, 2016), Bolter (BOLTER, 2016) e Kirschenbaum (2016) parece ser a minha, a qual não obtive permissão do HRC para disponibilizar.

Contudo, o que nos interessa saber aqui é que a primeira versão do Storyspace foi gestada, segundo conta em suas fontes documentais, entre os anos de 1985 e 1986. Seguiu-se, então, um período de implementações, antes de se tornar público. Período no qual, muito provavelmente, Joyce finalizou afternoon, a story ${ }^{11}$. Mas fato é que, quando terminado, o Storyspace foi apresentado oficialmente através da comunicação Hypertext and creative writing (1987) e de uma demonstração prática do programa em 1987 na ACM Hypertext'87 Conference, que ocorreu entre os dias 13 e 15 de novembro em Chapel Hill, onde Bolter residia e trabalhava.

\section{Pontos sobre a apresentação do Storyspace e o programa em si}

O texto, assinado apenas por Bolter e Joyce, apontava John Smith, colega de Bolter, como um dos cocriadores do Storyspace, e introduzia o programa como um sistema hipertextual que possibilitava a criação de um novo tipo de Ficção Interativa, cuja flexibilidade seria a principal característica. Segundo os autores, a partir desse novo tipo de Ficção Interativa o gênero adquiriria real valor literário.

Controversamente, o conteúdo do Markle Report (BOLTER; JOYCE, 1986) aponta apenas Bolter e Joyce como criadores do Storyspace, citando Smith apenas como um dentre os seus vários colaboradores. O próprio Smith, em entrevista a Barnet (2013), informou não ter participado do desenvolvimento do programa, nem de seus antecessores. Sua contribuição teria sido mais de ordem intelectual, ele ressalta, visto que o grupo que ele e Bolter integravam na UCN partilhava dos mesmos interesses. Moulthrop também já havia levantado essa questão em conversas comigo. Na sua opinião, o fato de Bolter, além de colega de trabalho e membro do grupo de Smith durante o desenvolvimento do Storyspace, ter acesso tanto às suas instalações quanto ao ambiente intelectual proporcionado por essa relação, o compeliu a incluir Smith como um dos seus criadores; o que é, para o bem ou para o mal, uma prática corriqueira na academia. Mas me arrisco a ir um pouco além.

Minha hipótese é que o nome de Smith, enquanto chefe do Departamento de Ciência da Computação da UCN, daria mais peso para o Storyspace frente à comunidade científica, uma vez que tanto Bolter quanto Joyce eram, na práti$\mathrm{ca}$, professores de Letras. Respaldo esse que seria muito importante para o lançamento do Storyspace no mercado, intenção explícita desde o Markle Report (BOLTER; JOYCE, 1986); tanto que, no ano seguinte, 1988, Bolter, Joyce e Smith fundaram a Riverrun Ltd. (BARNET, 2013) e, logo após, tentaram negociar, sem sucesso, os direitos do Stoyspace com a Brøderbund Software Inc., empresa que manufaturava jogos e softwares, responsável por títulos mundialmente famosos como Carmen Sandiego e Galactic Empire. 
Segundo Kirschenbaum (2008), que teve acesso à correspondência entre Joyce e a Brøderbund, as negociações encerraram em 1989 com uma negativa, sob o argumento de que havia tanto um enfraquecimento no mercado de software na época quanto uma dificuldade em determinar um público-alvo para o Storyspace. Há de se considerar, conforme Kirschenbaum (2017) levantou posteriormente, um cenário onde a resposta da Brøderbund tivesse sido afirmativa. Nele, muito provavelmente, o que entendemos hoje por Literatura Eletrônica teria tomado um rumo totalmente diferente, pois passaria a integrar as engrenagens de uma grande corporação cujos interesses giravam, principalmente, em torno de descobrir e satisfazer as demandas de mercado. Na prática, algo bem diferente do que aconteceu.

Paralelamente, na mesma ocasião, Joyce apresentou a todos os presentes na conferência a versão-beta do seu romance afternoon, a story (JOYCE, 1987). Mais do que a primeira obra escrita através do Storyspace, afternoon era a concretização do tipo de obra que Joyce tinha em mente quando pensou em desenvolver o programa, e foi disponibilizada gratuitamente em disquete junto com cópias do Storyspace para os participantes do evento. Ao contrário do Markle Report (BOLTER; JOYCE, 1986), a descrição do programa apresentada no artigo da ACM Hypertext'87 é consideravelmente curta, mas bastante didática, focando mais em suas funcionalidades do que em detalhes de ordem técnica. Nela, Bolter e Joyce (1987) informam a divisão do Storyspace em dois módulos: um autoral e outro de leitura.

O primeiro módulo possui um editor estrutural, usado pelo autor tanto para criar os episódios textuais que comporão a sua obra quanto para permitir simultaneamente uma visão gráfica e diagramática do processo que a compõe. Esses episódios textuais funcionam como uma rede de unidades, representadas visualmente na tela como caixas, que podem ser abertas para a inclusão de textos de extensão variada, além de serem movidas, adicionadas e deletadas a critério, de acordo com a estruturação desejada. Nele, o autor deve encerrar cada episódio informando ao leitor como esse deve proceder. Dentre as opções estão: responder a uma pergunta, fazer uma escolha ou simplesmente apertar um botão para continuar. As relações entre os episódios são representadas, visualmente, por setas desenhadas pelo autor, que indicam possíveis ordens de leitura para cada episódio. O editor interpreta essas setas como links, que carregam consigo sentenças condicionais definidas pelo autor.

As condições a serem satisfeitas para que se prossiga a um link seguinte podem ser de três tipos: 1) responder a uma pergunta de acordo com o que o sistema espera que seja respondido, 2) simplesmente já haver visitado determinado episódio, ou 3) uma combinação dessas condições, representada por meio de uma expressão booleana.

Através dessa lógica, o autor impõe ao leitor condições a serem satisfeitas dentro do seu percurso de leitura em uma obra criada a partir do Storyspace, dotando-o de uma liberdade controlada à medida que esses links condicionais acabam por atribuir algum grau de direcionamento diegético à leitura. São três os operadores booleanos comuns: $A N D, O R$ e NOT, e é por meio desse tipo de operadores que o autor define as condições de cada link. 
O segundo módulo do Storyspace, de leitura, proporcionava ao leitor uma visão diferente da obra, limitada aos conteúdos de cada episódio, com os quais ele poderia interagir, de acordo com a estipulação do autor, digitando algo ou apertando alguma tecla que o levasse para um próximo episódio. Ao passo em que o autor tanto enxerga quanto manipula o diagrama de evolução estrutural por trás de sua obra, o leitor tem acesso apenas ao texto. Toda primeira leitura começa a partir de um episódio inicial designado pelo autor. Para passar para o episódio seguinte o leitor deverá seguir o que lhe for solicitado, seja digitar algo ou apertar uma tecla. Essa ação será processada pelo sistema, que checará todos os links disponíveis para aquele episódio pela sua ordem de criação e encaminhará o leitor para o primeiro link cuja condição for satisfeita, e assim sucessivamente.

$\mathrm{O}$ artigo finda sem que seja feita uma única menção a afternoon, à exceção de uma frase em uma nota final, onde se lê: "Um de nós (o romancista Michael Joyce) está trabalhando atualmente com Ficção Interativa utilizando esse sistema [o Storyspace], e seu primeiro esforço, Afternoon, a Story [sic.] está disponível para leitores interessados" (BOLTER; JOYCE, 1987, p. 49, minha tradução ${ }^{12}$ ).

\section{Mark Bernstein e os desdobramentos que definiram a Literatura Eletrônica}

A ACM Hypertext'87 foi a primeira de uma série de conferências anuais dedicadas ao hipertexto, mantendo-se até os dias atuais; e pode ser tomada como o marco formal do início de uma estruturação dos estudos sobre Literatura Eletrônica. Talvez, por uma feliz coincidência, um caso fortuito de hora e local certos - não cabe aqui discutir -, mas é factual que aquela edição do evento conseguiu reunir, pela primeira vez, um número considerável de grandes nomes e expertises da produção e da crítica acerca do hipertexto e parte dos acontecimentos ali definiram os rumos da Literatura Eletrônica no seu país.

A conferência iniciou com a palestra de abertura de Theodor (Ted) Nelson, All for one and one for all, título que veio a se provar involuntariamente profético em um evento marcado pela interdisciplinariedade em torno de um tema cujo interesse das Humanidades causava, à primeira vista, estranheza à academia da época. Ocasião que aproximou estranhos e plantou, ou mesmo consolidou, a semente de parcerias e contribuições. Era o caso de Catherine C. Marshall, que no futuro se tornaria uma storyspacer - termo usado por Moulthrop para se referir aos membros da Eastgate School - através de sua obra Forward anywhere (MALLOY; MARSHALL, 1996), escrita em coautoria com Juddy Malloy, que assina como primeira autora, mas que naquele evento apresentava a sua comunicação Exploring representation problems using hypertext. Adicionalmente, fosse através das comunicações e/ou demonstrações, todos os grandes sistemas hipertextuais da época estavam presentes na Hypertext'87, segundo Bernstein em entrevista para Claus Atzenbeck (BERNSTEIN; ATZENBECK, 2008), incluindo os quatro futuros "concorrentes" do Storyspace. 
O primeiro era o GUIDE, introduzido por seu criador, Peter J. C. Brown, na comunicação Turning ideas into products: the Guide system; já o outro, o NoteCards, era analisado nas comunicações Hypertext habitats: experiences of writers in NoteCards de Randall H. Trigg e Peggy M. Irish, e Reflections on NoteCards: seven issues for the next generation of hypermedia systems de Frank G. Halasz. O terceiro grande sistema presente era o HyperCard, lançado pela Apple, que junto com todos os anteriores e o Storyspace, fez parte da sessão de demonstrações. Por último estava o Intermedia, que foi apresentado em relato de experiência sobre seu primeiro uso em sala de aula na comunicação Relationally encoded links and the rhetoric of hypertext, de George P. Landow. Seu autor - é válido aqui o parêntese - viria a se tornar o mais conhecido teórico e crítico de Literatura Eletrônica e hipertexto do mundo, pelo menos no que toca às fontes críticas das décadas de 1990 e 2000, fazendo-se ainda uma referência inevitável nos dias atuais. Sua contribuição teórica mais significativa para a área da Literatura Eletrônica se deu por meio de obras tais quais, Hypertext: the convergence of contemporary critical theory and technology (LANDOW, 1992), seguida de suas versões revisadas e apliadas, Hypertext 2.0 (LANDOW, 1997) e Hypertext 3.0: critical theory and technology in an age of globalization (LANDOW, 2006).

Não menos importante, presente nesse evento e em todos os que se seguiriam a partir dali, estava Mark Bernstein, cientista, editor-chefe e cofundador da Eastgate Systems. Fundada em 1982, a Eastgate era um misto de companhia de software e editora, e Bernstein, enquanto seu representante, estava no Hypertext'87 para demonstrar ao público o software de escrita hipertextual que ele havia desenvolvido, o Hypergate (BERNSTEIN, 1988). Mas não só isso. Como é praxe nesses eventos, também interessava a Bernstein o intercâmbio intelectual e os possíveis cont(r)atos propícios àquele ambiente.

Podemos ter uma ideia mais fiel do que o Hypertext'87 foi, significou e viria a significar, através do testemunho do próprio Bernstein:

Nos anos 1980 o mundo do hipertexto estava cheio de pessoas que construíram sistemas que incorporavam suas visões técnicas e teóricas. As demos no Hypertext'87 estavam literalmente no centro da conferência. Uma sala grande, vários grandes sistemas, sistemas sobre os quais nós tínhamos lido por anos, mas que, na verdade, você nunca tinha visto antes. Ali, em uma sala: o Xanadu, de Nelson; o NSL/Augment de Engelbart; o Symbolics Document Explorer, de Walker; Joyce e Bolter com o Storyspace; o meu Hypergate; Meyrowitz, Landow, Yankelovich e van Dam com o Intermedia. Havia o Black Magic, de Scott Johnson; o HyperTIES, de Ben Shneiderman; o HyperCard de Atkinson e o GUIDE de Brown. Você tinha várias ideias e vários softwares (BERNSTEIN; ATZENBECK, 2008, minha tradução ${ }^{13}$ ).

Bernstein, PhD em Físico-química pela Universidade de Harvard, havia largado seu emprego na equipe de pesquisa em IA da E. I. duPont de Nemours \& Co. - hoje a segunda maior empresa química do mundo - para retornar à Eastgate, em 1987, interessado em trabalhar, em suas próprias palavras, com "hipertexto, mani- 
pulação direta de interface e computação literária" (BERNSTEIN; ATZENBECK, 2008, minha tradução ${ }^{14}$ ), áreas que lhe pareciam as mais promissoras àquela época para uma pequena empresa de tecnologia, como sempre foi o caso da Eastgate.

Naquele evento, ele conheceu Bolter, Joyce e o Storyspace, mas o que realmente despertou seu interesse, segundo Barnet (2013), foi afternoon, a Hiperficção de Joyce, uma vez que o Storyspace era só mais um - relativamente simples, diga-se de passagem - dentre os outros tantos sistemas hipertextuais apresentados na conferência. Tanto que na negociação com a Eastgate, Joyce tentou barganhar a aquisição dos direitos de afternoon, como uma espécie de pacote, à aquisição e ao licenciamento do Storyspace e não o contrário. Bernstein e Joyce compartilhavam dessa característica comum: ambos estavam interessados, cada um a seu modo, nas aplicações empíricas desses sistemas hipertextuais para a literatura, ou seja, queriam obras em hipertexto. Joyce, enquanto autor, desejava concretizar, ele mesmo, esse tipo de obra; ao passo que Bernstein, enquanto editor, desejava pôr, não apenas metaforicamente, as mãos nessas obras.

Sua urgência por um maior aproveitamento desses recursos tecnológicos para se fazer literatura ficou registrada na indagação que ecoou nos corredores e nos painéis do Hypertext'89 em Pittsburgh, na Pensilvânia. "Onde estão os hipertextos?” (BERNSTEIN; ATZENBECK, 2008, minha tradução ${ }^{15}$ ), Bernstein queria saber. E a pergunta continuou sendo repetida 27 anos depois, no Hypertext'16 em Halifax, Canadá (BERNSTEIN, 2016), como um protesto de longa data contra a disparidade entre a quantidade e a diversidade crescente de ferramentas proporcionadas pela tecnologia e a quantidade de obras produzidas a partir delas. Como aponta Barnet (2013, p. 133, minha tradução $\left.{ }^{16}\right)$, "Bernstein procurou encontrar e publicar hipertextos porque sentia que o mundo literário precisava de alguns exemplos reais; tudo era teoria do hipertexto, mas [na prática] não havia nenhum 'hipertexto de verdade". Daí podemos entender melhor o seu claro interesse em afternoon. Ao adquiri-lo, Bernstein conseguiu finalmente algo que corporificava o que tanto se discutia na teoria. Uma demonstração prática. O que, por vezes, é bem mais efetivo que a melhor das explicações; assim, ao invés de se elucubrar sobre a Literatura Eletrônica apenas no terreno do abstrato, era possível observar a corporificação de um acontecimento de escrita hipertextual.

Outro aspecto que não podemos deixar escapar é a importância do que representaria a figura de Joyce para Bernstein. Tratava-se não só de um romancista premiado, mas de um professor de ensino superior com acesso aos círculos acadêmicos onde se encontravam os pesquisadores daquele campo incipiente. Era esperado, portanto, que alguém com essas credenciais desfrutasse de alguma vantagem - o que se provou, para o bem ou para o mal, uma verdade - em comparação a algum outro escritor, mesmo de Literatura Eletrônica, menos conhecido. Daí uma das possíveis razões pela qual afternoon teve uma recepção tão positiva da crítica interessada naquele gênero ainda por nascer, o que acabou alavancando - na esteira, mas sem diminuir seus méritos próprios - a Eastgate e o Storyspace.

Por fim, o contrato com a Eastgate foi assinado em 17 de dezembro de 1990, e a partir de então Bernstein se tornou um dos nomes mais importantes da histó- 
ria da Literatura Eletrônica e a maior autoridade no que concerne ao Storyspace. Dessa forma, nasceu a Eastgate School, o grupo de autores de Literatura Eletrônica ligados à Eastgate Systems.

Bem antes da assinatura do contrato com a Eastgate, no entanto, além da apresentação do Storyspace, a grande preocupação de Bolter e Joyce (1987) em seu artigo era, claramente, enquadrar o que eles chamaram de Ficção Interativa em Hipertexto - distinção que eles fizeram dentro do termo que haviam tomado de empréstimo - dentro de alguma tradição literária reconhecida pela crítica, numa busca evidente pela sua validação dentro do meio acadêmico e por um distanciamento dos Jogos de Aventura. Ação que eles imaginaram ser o caminho para que o Storyspace entrasse no mercado. No caso, essa tradição seria a literatura experimentalista do século XX, mais especificamente “[...] o modernismo, futurismo, dadaísmo, surrealismo, letrismo, o nouveau roman, a poesia concreta e outros movimentos de maior ou menor influência" (BOLTER; JOYCE, 1987, p. 44, minha tradução ${ }^{17}$ ), como é o caso do OuLiPo. E aí entrava a importância de já terem em mãos uma obra da qual pudesse partir essa comparação, que, no caso, era afternoon.

Teóricos como Ensslin (2007, 2014); Bell, Ensslin e Rustad (2014); Kirschenbaum (2008); Bernstein e Atzenbeck (2008) e Rettberg (2015) apontam, contudo, que a base dessa influência, longe de ser apenas literária, era fortemente construída sobre um referencial teórico. O que não é de se causar espanto, uma vez que a produção massiva em Literatura Eletrônica dos anos 1990 que recebeu alguma atenção da crítica é de acadêmicos que, não coincidentemente, constituíam essa mesma crítica, ou estavam inseridos em círculos ligados a ela, como Bolter, Joyce, Moulthrop, Bernstein e praticamente todos os outros membros da Eastgate School; e que seu público era, também, majoritariamente acadêmico.

As grandes influências literárias seriam não apenas o modernismo, como citado por Bolter e Joyce, mas também o pós-modernismo, de acordo com Bernstein (BERNSTEIN; ATZENBECK, 2008) e Rettberg (2015). Já a base teórica por trás das obras e da crítica seria o pós-estruturalismo enquanto desdobramento do estruturalismo, por meio de preceitos como "a morte do autor, a descentralização do significado e da coerência textual, a metáfora do rizoma, a antilineariedade e a noção de [...] 'lexia”' (ENSSLIN, 2007, p. 40-41, minha tradução ${ }^{18}$ ), que ficam implícitos na menção feita por Bolter e Joyce (1987) ao grupo Tel Quel.

Ao se tratar dessa influência no estado da arte da Literatura Eletrônica, ela é constantemente atribuída à compatibilidade do referencial teórico pós-estruturalista com aquilo a que se propunha o gênero. Entretanto, há de se levar em conta um fator histórico-biográfico que passa despercebido, que é a formação dos teóricos da primeira leva da Literatura Eletrônica. Nascidos entre as décadas de 1940 e 1950, cursaram o ensino superior nos anos 1960 e 1970, auge do pós-estruturalismo. Dessa feita, é válido supor o quão influente essa corrente teórica tenha sido para sua formação e, posteriormente, para sua vida profissional enquanto docentes. E mais do que isso, o quanto seus conceitos se imbuíram no fazer literário de romancistas crias da academia, como Joyce. 
Isso me leva a conjecturar que esse diálogo entre a Literatura Eletrônica e tal referencial teórico se deve a um cenário em que o pós-estruturalismo era o que se tinha à mão de mais atual, portanto, seria natural o seu uso. Tivesse a Literatura Eletrônica despontado na década de 1950, ela muito provavelmente seria encarada pela ótica do New Criticism, à época a corrente mais expressiva nos Estados Unidos. Também é observável que a práxis da Literatura Eletrônica, tanto em um primeiro momento quanto repetidas vezes ao longo desses anos, tenha se inspirado, acima de tudo, em conceitos advindos de modelos teórico-críticos usados posteriormente para sua retrovalidação. Dessa forma, em última instância, o uso do argumento teórico baseava-se, na realidade, em uma tentativa de valorizar o seu produto para o público ainda não formado ao qual ele se destinaria. Controversamente, parte dessa estratégia baseou-se em diminuir a Ficção Interativa num momento em que ela já não estava mais em seu ápice.

\section{Considerações sobre o fim dos anos 1980: a Literatura Eletrônica não estava para jogos}

Como resultado da evolução tecnológica do computador, conforme se aproximava o final da década de 1980, os avanços na área permitiram o desenvolvimento de interfaces gráficas cada vez mais complexas (MONTFORT, 2003; RYAN, 2005; HUTCHISON, 2009), o que prenunciou o declínio da Ficção Interativa. Pois diante do apelo visual dessas novas interfaces e do aumento das capacidades gráficas dos computadores, os jogos baseados em texto começaram a ser considerados ultrapassados por sua clientela.

Uma explicação para isso, conforme Espen Aarseth (1997, p. 102, minha tradução ${ }^{19}$ ), reside no fato de que "imagens, especialmente imagens que se movem, são representações mais poderosas de relações espaciais do que textos e, por consequência, essa migração do texto para o gráfico é natural e inevitável". Até poderíamos fazer um paralelo entre a literatura e o cinema a partir dessa citação, mas o surgimento do segundo há mais de um século, embora tenha tido seus efeitos sobre a primeira, não resultou em sua queda, como todos pudemos testemunhar.

O que se pode ver em Ryan (2005), mesmo que implícito, é que essa maior capacidade gráfica dos computadores foi um dos grandes responsáveis por separar, pelo menos naquele momento, jogos (videogames) e literatura. Separação justificada pelo aumento no grau de ludicidade conferido aos jogos. Assim, o chamado fim da Ficção Interativa seria, na realidade, uma bifurcação. Pois, da mesma forma que a evolução tecnológica possibilitou uma maior capacidade gráfica que foi direcionada para a indústria dos jogos e videogames, ela também permitiu o surgimento de um novo gênero literário baseado na tecnologia. Gênero que viria a ser considerado, problematicamente, o sucessor natural da Ficção Interativa: a Ficção em Hipertexto, ou Hiperficção, que nasceu oficialmente junto com o Storyspace.

Ao pé da letra, a Hiperficção não é a sucessora da Ficção Interativa, nem sua evolução direta. O que se pode afirmar é que autores como Joyce foram influenciados pelo gênero, chegando, inclusive, a utilizar de empréstimo o termo 
Fiç̧ão Interativa, na falta de um outro à época, para definir o tipo de literatura à qual almejavam com o Storyspace. Apesar disso, não houve uma migração, pois criadores de Ficção Interativa não se tornaram autores de Ficção em Hipertexto. Nem a indústria dos games absorveu a Hiperficção após o colapso da Ficção Interativa, como pode ser exemplificado pela recusa na aquisição dos direitos do Storyspace pela Brøderbund Software Inc.

Diferente da indústria de games, a expansão comercial da Ficção Interativa dependia também da expansão da indústria de computadores. E enquanto as evoluções tecnológicas da indústria de games eram voltadas ao seu produto, a evolução da indústria de computadores não era voltada para a evolução da indústria de Ficção Interativa. Nesse quesito, sobrava à Ficção Interativa fazer uso do que lhe era disponibilizado, o que significou uma clara desvantagem.

Avaliando por esse ângulo, vemos que o uso da matéria verbal era, na realidade, uma forma de contornar uma deficiência nas capacidades gráficas dos computadores que ainda estaria para ser suprida. Dessa feita, não seria de todo incorreto posicionar a Ficção Interativa também em um meio-termo, mutatis mutandis, dentro da evolução dos jogos eletrônicos e videogames, não como sua precursora, como pode parecer, dependendo da fonte, mas como uma resposta integrada a eles. Pois tem-se notícia dos primeiros protótipos de jogos eletrônicos - simulações pragmáticas de caráter não-lúdico, no caso - desde o início da década de 1950, com os primeiros computadores. Da mesma forma, a indústria de videogames já era um negócio em ascensão com seus fliperamas desde o começo dos anos 1970. Coincidência ou não, o primeiro console de videogame, o Odyssey, fabricado pela Magnavox, passou a ser comercializado nos Estados Unidos em 1972, mesmo ano de criação de Colossal Cave Adventure. Assim, pode-se se considerar que os desenvolvimentos paralelos de ambas as indústrias, a dos $v i$ deogames e a da Ficção Interativa, protagonizaram uma espécie de convergência episódica ao longo da década de 1980, quando ambas logravam sucesso comercial. No caso da indústria de videogames, esse sucesso tem se mantido em uma constante crescente desde então; ao contrário da Ficção Interativa, e também de sua dita sucessora, a Literatura Eletrônica.

Em análise, é plausível inferir que a Ficção Interativa encontrou seu nicho - não somente, mas também devido à - na lacuna gráfica dos computadores de sua época, como uma forma de contorná-la. Consequentemente, não é em nada absurdo afirmar que sua motivação a aproxima mais da indústria dos videogames do que da indústria literária, pois o material literário (o texto) lhe era um veículo para outro propósito que não a fruição literária. Já quanto à observância de sua literariedade, ela me parece uma questão simplesmente circunstancial. Pelo menos na época. Basta que se leve em conta que o ano de 1984, segundo Aarseth (1997), foi o pontapé do interesse da crítica nas propriedades literárias dos textos mediados via computador. E não há crítica sem material para ser criticado. Por isso, não me parece acaso o surgimento desse interesse na Fiç̧ão Interativa no ano de maior vendagem e valorização do valor de mercado da Infocom, que passou a ser considerada de acordo com Jimmy Maher (2006), a empresa líder no segmento 
de jogos de computador no final de 1983.

Nessa época, a Ficção Interativa contava com uma cadeia de produção e distribuição formal, somada a (e de certa forma resultado de) uma visibilidade que lhe chancelava e aproximava das massas. E se hoje se sabe de outras produções literárias em meio eletrônico contemporâneas à Ficção Interativa que não receberam, pelo menos em volume, a mesma atenção do público e da crítica, deve-se considerar o quão rudimentar - comparada aos dias atuais - era a circulação de informação nos anos 1980. Desse modo, para além da lacuna da indústria de videogames e jogos eletrônicos, no que concerne à Literatura Eletrônica, tudo indica que a Ficção Interativa serviu aos interesses de uma teoria e uma crítica incipientes, que precisavam apoiar pelo menos parte de suas pesquisas e escritos em algo factível, de acesso a um grande público. Mesmo que esse algo não fosse exatamente o que eles esperavam, ainda que sob o risco de criar um remendo teórico.

Essa questão epistemológica não é exclusividade da Literatura Eletrônica, mas a acompanha desde sua gênese. Como também foi observado por Aarseth, que, nesse caso - e sobre esse caso em específico -, foi uma voz dissonante dentro da área:

[As] teorias da literatura possuem uma habilidade poderosa de cooptar novos campos e preencher vácuos teóricos, e nesse processo de colonização, onde o "território virgem" carece de uma defesa teórica, perspectivas e insights importantes podem se perder ou serem, no mínimo, negligenciados (AARSETH, 1997, p. 18-19, minha tradução ${ }^{20}$ ).

Destarte, em se tratando da Ficção Interativa, a problemática que vejo não foi o seu deslocamento para o campo do literário pela crítica, mas a circunstancialidade que impediu uma abordagem fenomenológica legítima frente às noções ainda em construção do que viria a ser aquele tipo de literatura, da qual a Ficção Interativa constituiria, para ser honesto, um guia mais pelas aplicações do suporte do que por suas pretensas qualidades literárias. Então, como uma resposta, ao meu ver exagerada, a comunidade de autores, teóricos e críticos de Literatura Eletrônica passou a rechaçar a Ficção Interativa como algo menor quando a Hiperficção começou a se estabelecer, uma vez que a última, sim, correspondia mais fidedignamente às suas visões contemporâneas do que viria a ser a Literatura Eletrônica. E como se pode ver em Noah Wardrip-Fruin, parte da comunidade que formaria a Eastgate School constituía a linha de frente dessa caça às bruxas:

"Isto não é um jogo" foi, durante um tempo, um slogan adotado por um grupo de escritores e teóricos do hipertexto. Enquanto ele é frequentemente remetido a uma oficina de escrita em hipermídia dirigida por Rob Swigart [futuro membro da Eastgate School] em 1988, o seu proponente mais notável era John McDaid [também futuro membro da Eastgate School]. [...] Dentre outros proponentes do slogan, incluíamse membros notórios da comunidade hipertextual, como Stuart Moulthrop e Michael Joyce (WARDRIP-FRUIN, 2005, minha tradução) ${ }^{21}$. 
Das motivações pessoais por trás desse posicionamento, Moulthrop confessa que havia, de fato, uma certa inveja do sucesso comercial e de público da Infocom (WARDRIP-FRUIN, 2005). E que essa posição só começou a ser revista quando se deram conta de que aquela atitude era uma reprodução do que ocorria com a própria Literatura Eletrônica - melhor representada, a partir dessa visão, pela Hiperficção -, vista pela crítica geral como um subgênero de menor importância. Uma diferença, entretanto, foi que esse posicionamento explícito da comunidade da Hiperfição nunca afetou, de fato, a Ficção Interativa. Afinal, eles eram apenas uma pequena parte da academia e tanto o mercado quanto o público-alvo da Ficção Interativa, ao contrário da Fiç̧ão em Hipertexto, não estavam condicionados à crítica acadêmica.

Justamente por não padecer dessa restrição, a Ficção Interativa constituiu um mercado lucrativo de uma forma que a Hiperficção apenas sonhou. A última, ao contrário, fechou-se desde o seu nascimento à academia e ao repelir a Ficção Interativa, tratando-a e aos videogames como algo inferior, acabou por repelir todo um público consumidor. Público esse que, por extensão, não seria qualificado o suficiente para consumir o seu produto e que rendeu à indústria dos videogames e jogos de computador e celular, para se ter uma ideia do seu tamanho nos dias de hoje, uma receita de 34,5 bilhões de dólares, apenas nos Estados Unidos, no ano de 2019, segundo dados disponíveis no sítio da Entertainment Software Association (ESA).

Dessa feita, o final dos anos 1980 testemunhou o nascimento da década de ouro da Literatura Eletrônica nos Estados Unidos a partir do subgênero que melhor incorporou as aspirações téoricas, conceituais e estéticas da época. E, assim, a Hiperficção, mesmo nunca tendo alcançado algo próximo ao sucesso comercial da Ficção Interativa, viveu o seu ápice nos anos 1990, quando os nomes Eastgate e Storyspace tornaram-se praticamente sinônimos de Literatura Eletrônica. Pois foi em torno deles que se formou o que hoje veio a ser reconhecido como o único corpus homogêneo quando se fala não apenas na Literatura Eletrônica produzida nos Estados Unidos, mas em todo o mundo. Assim como o grupo a formar o que seria a única, se assim considerada, escola literária dentro do gênero: a Eastgate School, que por pouco não monopolizou, ao longo da década de 1990, a criação, teoria e crítica na Literatura Eletrônica estadunidense.

\section{Agradecimentos}

Agradeço a Stuart Moulthrop, Michael Joyce, Jay Bolter, Mark Bernstein, Nick Montfort e Matthew Kirschenbaum pela disponibilidade e pelas contribuições inestimáveis. À Universidade de Wisconsin, Milwaukee, e ao Harry Ransom Center da Universidade do Texas, em Austin, pela disponibilidade do espaço físico e de parte das fontes bibliográficas aqui utilizadas. Por fim, a pesquisa que originou este artigo contou com o apoio financeiro da Fundação de Amparo à Pesquisa do Estado do Piauí (FAPEPI), da Coordenação de Aperfeiçoamento de Pessoal de Nível Superior (CAPES) e da Comissão Fulbright Brasil. 
Notas

1. Texto adaptado a partir da Introdução e dos Capítulos 1 e 3 da tese de doutoramento Criação, teoria e crítica na literatura eletrônica estadunidense (MOURA, 2018), do Programa de Pós-Graduação em Literatura da Universidade Federal de Santa Catarina (UFSC), sob orientação do Prof. Dr. Alckmar Luiz dos Santos e coorientação do Prof. Dr. Stuart Moulthrop (Universidade de Wisconsin, Milwaukee).

2. No original: "work with an important literary aspect that takes advantage of the capabilities and contexts provided by the stand-alone or networked computer" (HAYLES, 2007, p. 4).

3. No original: "hypertext fiction and poetry, on and off the web; / kinetic poetry presented in Flash and using other platforms; / computer art installations that ask viewers to read them or otherwise have literary aspects; / conversational characters, also known as "chatterbots"; / interactive fiction; / novels that take the form of e-mails, SMS messages, or blogs; / poems and stories that are generated by computers, either interactively or based on parameters given at the beginning; / collaborative writing projects that allow readers to contribute to the text of a work; / literary performances online that develop new ways of writing" (RETTBERG, 2014, p. 172).

4. No original: "This text only interface was necessary because the computers of the 1970 s had little or none of the visual capability that would allow any audio-visual rendering/ description of the scenes, or the 'point and click' interface that would become more usual by the end of the 1980s. The system uses a technique called 'parsing' to analyse the user's input, and then either responds appropriately, or else, as is often the case, prompts the player to rephrase the input in a manner the 'parser' can respond to usefully. This language parsing technique attempts to allow the player to use normal language to Interact with the game through the keyboard only" (HUTCHISON, 2009, p. 52-53).

5. No original: "a successor game to Adventure" (HUTCHISON, 2009, p. 56).

6. No original: "So I'm writing to ask you what to do after you turn it on. Seriously, I am and have been spending long, timeless nights learning my way around this/that thing, and this night I've turned myself outward for some correspondence, and the shift is salutary I think. I am amazed by how compelling the computer is, how freely I am able to write at it (confined to journals as yet, until I get the fine points of Applewriter down), and how easily time goes by at its terminal. But I am aware of its inwardness, a sense that time spent there is burrowing and silent, somehow geometric. Possibly this really is a function of not having the printer as yet, but I doubt so. I think it has more to do with the utterly elemental quality of the information the Apple handles, the really quite pleasing beauty of the rows of chips when the lid is off, the pleasant geographic satisfaction of memory simultaneously on the disk and in memory itself, the ribbed, grey ribbon that links them. I mean, this is seductive technology. A friend asked whether I wasn't bothered by the fact that there is no paper before me, as now, and I honestly had to answer that, if anything, using the computer seemed a more authentic way of capturing language as I understand it. Words seem more like the hive of electronic hashmarks to me than these carbon strikes before me. It seems right to construe language as a series of switchmarks, loads and unloads, zeros and ones. The form it eventually takes is almost incidental; do we always write down dreams? (I'm surprised by the weight of the "pleasing" and "pleasant" above, but it's the language that comes. A computer, an Apple especially, is a very clean machine)" (JOYCE, 1982).

7. No original: "What I really wanted to do, I discovered, was not merely to move a paragraph from page 265 to page 7 but to do so almost endlessly. I wanted, quite simply, to write a novel that would change in successive readings and to make those changing versions according to the connections that I had for some time naturally discovered in the process of writing and that I wanted my readers to share. In my eyes, paragraphs on many different pages could just as well go with paragraphs on many other pages, although with different effects and for different purposes. All that kept me from doing so was the fact that, in print at least, one paragraph inevitably follows another. It seemed 
to me that if I, as author, could use a computer to move paragraphs about, it wouldn't take much to let readers do so according to some scheme I had predetermined" (JOYCE, 1995, p. 31).

8. No original: “multiple fictions” (BOLTER; JOYCE, 1986, p. 12).

9. No original: “a tree structured writing support system” (BOLTER; JOYCE, 1986, p. 13).

10. No original: "The relatively complex data structure which we agreed upon nonetheless involves generally known techniques for representing data in computers. The method devised involved storing "nodes" consisting of text, digitally stored images, and so on, together with the network of "links" between those nodes, in such a way that both, the creator and the audience could process, transfer, and receive them in remarkable subtle ways. More particularly, it involved combining the relatively familiar and efficient hierarchical data structure known as the tree with the less familiar but more robust data structure known as networks or graphs" (BOLTER; JOYCE, 1986, p. 13).

11. A grafia correta do título é toda em letra minúscula, embora não seja incomum, no que concerne às menções à obra, vê-la erroneamente referida como Afternoon, $a$ story, iniciando com letra em caixa-alta.

12. No original: "One of us (novelist Michael Joyce) is currently working on interactive fiction using this system, and his first effort, "Afternoon, a Story" [sic] is available to interested readers" (BOLTER; JOYCE, 1987, p. 49).

13. No original: "In the 1980's, the hypertext world was filled with people who built systems that embodied their technical and theoretic vision. The demos at Hypertext ' 87 were literally at the center of the conference. One big room, lots of big systems, systems we'd been reading about for years but that you'd never actually seen before. There in one room: Ted Nelson's Xanadu, Engelbart's NLS/Augment, Walker's Symbolics Document Explorer, Joyce and Bolter with Storyspace, my Hypergate, Meyrowitz and Landow and Yankelovich and van Dam with Intermedia. There was Scott Johnson's Black Magic, and Ben Shneiderman's HyperTIES, and Atkinson's HyperCard, and Peter Brown's Guide. You had lots of ideas and lots of software" (BERNSTEIN; ATZENBECK, 2008).

14. No original: "Hypertext, direct-manipulation interfaces, and Literate Computing" (BERNSTEIN; ATZENBECK, 2008).

15. No original: “Where are the hypertexts?” (BERNSTEIN; ATZENBECK, 2008).

16. No original: "Bernstein sought to find and publish hypertexts because he felt the literary world needed some real examples; it was all hypertext theory, no 'serious hypertext" (BARNET, 2013, p. 133).

17. No original: "modernism, futurism, Dada, surrealism, letterism, the nouveau roman, concrete poetry, and other movements of greater or lesser influence" (BOLTER; JOYCE, 1987, p. 44).

18. No original: "the death of the author, the decentralization of textual meaning and coherence, the rhizome metaphor, antilinearity, and the notion of [...] 'lexia"' (ENSSLIN, 2007, p. 40-41).

19. No original: "Images, especially moving images, are more powerful representations of spatial relationships than texts, and therefore this migration from text to graphics is natural and inevitable" (AARSETH, 1997, p. 102).

20. No original: "Theories of literature have a powerful ability to co-opt new fields and fill theoretical vacuums, and in such a process of colonization, where the "virgin territory" lacks theoretical defense, important perspectives and insight might be lost or at least overlooked" (AARSETH, 1997, p. 18-19).

21. No original: "This is not a game" was a slogan, at one time, embraced by a group of hypertext writers and theorists. While it is often traced back to a 1988 hypermedia writing workshop run by Rob Swigart, the slogan's most visible proponent was John McDaid. [...] Other proponents of the slogan included high-profile members of the hypertext community such as Stuart Moulthrop and Michael Joyce" (WARDRIP-FRUIN, 2005). 


\section{Referências}

ADAMS, D.; MERETZKY, S. The hitchhiker's guide to the galaxy. [Jogo] Cambridge: Infocom, 1984.

AARSETH, E. J. Cybertext: perspectives on ergodic literature. Baltimore: Johns Hopkins University Press, 1997.

BARNETT, B. Memory machines: the evolution of hypertext. Nova York: Anthem Press, 2013.

BELL, A.; ENSSLIN, A; RUSTAD, H. K. From theorizing to analysing digital fiction. In: BELL, A.; ENSSLIN, A; RUSTAD, H. K. Analysing digital fiction. Nova York: Routledge, 2014. p. 3-17.

BERNSTEIN, M. Storyspace 3. HT'16 - Proceedings of the 27th ACM Conference on Hypertext and Social Media. Halifax, ACM: 2016. DOI: https://doi. org/10.1145/2914586.2914624.

BERNSTEIN, M. The bookmark and the compass: orientation tools for hypertext users. ACM SIGOIS Bulletin, v. 9, n. 4, p. 34-45, out, 1988. DOI: https://doi. org/10.1145/51640.51645.

BERNSTEIN, M. The Tinderbox way. Watertown: Eastgate Systems, 2017.

BERNSTEIN, M.; ATZENBECK, C. Interview with Mark Bernstein. ACM SIGWEB newsletter, Nova York, v. 2008, n. 4, p. 1-5, verão, jun. 2008. DOI: https://doi. org/10.1145/1377501.1377505.

BOLTER, J. D. The idea of literature in the electronic medium. Topic, v. 39. p. 23-34, Fall, 1985.

BOLTER, J. D. Turing's man: western culture in the computer age. Chapel Hill: The University of North Carolina Press, 1984.

BOLTER, J. D. [About the Markle Report on Storyspace]. Remetente: Cláudio Augusto Carvalho Moura. [S. l.], 16 ago. 2016. Mensagem recebida por e-mail: ca.carvalho@ufpi.edu.br.

BOLTER, J. D.; JOYCE, M. Hypertext and creative writing. Proceedings of Hypertext 1987. New York: ACM, 1987. DOI: https://doi.org/10.1145/317426.317431.

BOLTER, J. D.; JOYCE, M. STORYSPACE: a tool for interaction, report to the Markle Foundation regarding G85105. 1986. Disponível em: https://elmcip.net/ node/5253. Acesso em: 20 jul. 2019.

BOLTER, J. D.; JOYCE, M.; KRAKOWIAK, J. Notes on the collaborative effort to create a data structure for interactive fiction. In: Michael Joyce Papers. Harry Ransom Humanities Research Center, University of Texas at Austin, 1984.

BROCA, B. A vida literária no Brasil-1900. 5. ed. Rio de Janeiro: Academia Brasileira de Letras, 2005.

CHANDLER, A. D. Inventing the electronic century: the epic story of the consumer electronics and computer industries. Cambridge: Harvard University Press, 2009.

CROWTHER, W. Colossal Cave Adventure, 1972 (Programa de Computador).

CROWTHER, W.; WOODS, D. Adventure: the interactive original, 1977. Disponível em http://www.web-adventures.org/cgi-bin/webfrotz?s=Adventure. Acesso em: 04 abr. 2020.

DEHN, N. Story generation after Tale-Spin. Proceedings of the Seventh International Conference on Artificial Intelligence, Los Altos: William Kaufmann, v. 1, p. 16-18, 1981. 
DOUGLAS, J. Y. I have said nothing. Watertown: Eastgate Systems, 1994. 1 CD-ROM.

ENSSLIN, A. Canonizing hypertext: explorations and construction. Londres: Continuum, 2007.

ENSSLIN, A. Hypertextuality. In: RYAN, M.; EMERSON, L.; ROBERTSON, B. J. (Orgs.). The Johns Hopkins guide to digital media. Baltimore: The Johns Hopkins University Press, 2014. p. 258-265.

ENTERTEINMENT SOFTWARE ASSOCIATION. U.S. video game content generated \$35.4 billion in revenue for 2019. 23 de janeiro de 2020. Disponível em https://www.theesa.com/press-releases/u-s-video-game-content-generated-354-billion-in-revenue-for-2019/. Acesso em: 10 mar. 2020.

FRIEDRICH, O. The computer moves in. TIME, Nova York, v. 121, n. 1, 03 jan. 1983.

GEYH, P.; LEEBRON, F. G.; LEVY, A. From afternoon, a story. In: GEYH, P.; LEEBRON, F. G.; LEVY, A. (Eds.). Postmodern American fiction: a Norton anthology. Nova York: W. W. Norton \& Company, 1997. p. 577-580.

GEYH, P.; LEEBRON, F. G.; LEVY, A. From I had said nothing. In: GEYH, P.; LEEBRON, F. G.; LEVY, A. (Eds.). Postmodern American fiction: a Norton anthology. Nova York: W. W. Norton \& Company, 1997. p. 574-575.

HAYLES, N. K. Electronic Literature: what is it?. Electronic Literature Organization, v. 1.0, 2 jan. 2007. Disponível em: https://eliterature.org/pad/elp.html. Acesso em: 13 abr. 2019.

HUSSERL, E. Meditações cartesianas: introdução à fenomenologia. Tradução de F. Oliveira. Alto de Santana: Madras, 2001.

HUTCHISON, A. Techno-historical limits of the interface: the performance of interactive narrative experiences. 2009. 220 p. Thesis (PhD) - School of Media, Culture, and Creative Arts, Department of Communication and Cultural Studies, Curtin University of Technology, Perth, 2009.

JACKSON, S. Patchwork girl. Watertown: Eastgate Systems, 1995 (CD-Rom).

JOYCE, M. [About the Markle Report on Storyspace]. Remetente: Cláudio Augusto Carvalho Moura. [S. l.], 17 ago. 2016. Mensagem recebida por e-mail:ca.c arvalho@ufpi.edu.br.

JOYCE, M. afternoon, a story. In: Michael Joyce Papers. Harry Ransom Humanities Research Center, University of Texas at Austin, 1987 (Disquete).

JOYCE, M. afternoon, a story. Watertown: Eastgate Systems, 1990 (CD-Rom).

JOYCE, M. [Correspondência pessoal]. Destinatário: Howard Saul Becker. 7 jan. 1982. Cartas. In: Michael Joyce Papers. Harry Ransom Humanities Research Center, University of Texas at Austin, 1982.

JOYCE, M. Draft of pseudocode for text processor. In: Michael Joyce Papers. Harry Ransom Humanities Research Center, University of Texas at Austin, 1984.

JOYCE, M. Of two minds: hypertext pedagogy and poetics. Jackson: University of Michigan Press: 1995.

JOYCE, M. The war outside Ireland: a novel. Jackson: Tinkers Dam Press, 1982.

KIRSCHENBAUM, M. G. [A question about your "Mechanisms"]. Remetente: Cláudio Augusto Carvalho Moura. [S. l.], 9 jul. 2017. Mensagem recebida por e-mail: ca.carvalho@ufpi.edu.br.

KIRSCHENBAUM, M. G. [About the Markle Report]. Remetente: Cláudio Augusto Carvalho Moura. [S. l.], 10 out. 2016. Mensagem recebida por e-mail: ca.carvalho@ ufpi.edu.br. 
KIRSCHENBAUM, M. G. Mechanisms: new media and forensic imagination. Cambridge-MA: The MIT Press, 2008.

LANDOW, G. P. Hypertext: the convergence of contemporary critical theory and technology. Baltimore: The Johns Hopkins University Press, 1992.

LANDOW, G. P. Hypertext 2.0. Baltimore: The Johns Hopkins University Press,1997.

LANDOW, G. P. Hypertext 3.0: critical theory and technology in an age of globalization. Baltimore: The Johns Hopkins University Press, 2006.

MAHER, J. Let's tell a story together: a history of Interactive Fiction. 2006. Disponível em: http://maher.filfre.net/if-book/. Acesso em: 10 nov. 2019.

MALLOY, J.; MARSHALL, C. Forward anywhere. Watertown: Eastgate Systems, 1996 (CD-Rom).

MONTFORT, N. Twisty little passages: an approach to interactive fiction. Cambridge: The MIT Press, 2003.

MOULTHROP, S. Victory Garden. Watertown: Eastgate Systems, 1991 (CD-Rom).

MOURA, C. A. C. Criação, teoria e crítica na literatura eletrônica estadunidense. 2018, 255 f. Tese (Doutorado em Literatura) - Centro de Comunicação e Expressão, Universidade Federal de Santa Catarina, Florianópolis, 2018.

RETTBERG, S. Electronic literature. In: RYAN, M.; EMERSON, L.; ROBERTSON, B. J. (Eds.). The Johns Hopkins guide to digital media. Baltimore: The Johns Hopkins University Press, 2014. p. 196-174.

RETTBERG, S. Electronic Literature seen from a distance: the beginnings of a field. Dichtung digital, v. 41, 2012. Disponível em: http://www.dichtung-digital. org/2012/41/walker-rettberg.htm. Acesso em: 19 jul. 2019.

RETTBERG, S. The American hypertext novel, and whatever became of it? In: KOENITZ, H. et al. (Eds.). Interactive digital narrative: history, theory and practice. Nova York: Routledge, 2015. p. 22-35.

RYAN, M. Narrative and digitality: learning to think with the medium. In: PHELAN, J.; RABINOWITZ, P.J. A companion to narrative theory. Malden: Blackwell Publishing, 2005. p. 517-528.

SOKAL, A.; BRICMONT, J. Imposturas intelectuais. Tradução de Max Altman. Rio de Janeiro: Record, 1999.

TIME. Nova York: Time Inc., v. 121, n. 1, 03 jan. 1983.

WARDRIP-FRUIN, N. Playable media and textual instruments. Dichtung Digital, v. 34, p. 211-254, 2005. DOI: https://doi.org/10.14361/9783839404935-010.

Recebido em: 16/06/2020 Aceito em: 30/07/2020 